\title{
materias sintéticas como auxiliares en la construcción con hormigón
}

\author{
«Betonștein-Zeiturngm, núm, 4, abril 1961, på. 200
}

El desarrollo técnico de los materiales sintéticos abre hoy día, en la construcción de hormigón, muchas nuevas posibilidades de aplicación. Este hecho quedó demostrado por la empresa química Hüls AG, quien dio ocasión, a la prensa especializada, de visitar una exposición bajo el tema «Materias sintéticas de Hüils en la construcción» y a la cual siguió una conferencia. Para demostrar las amplias posibilidades de este material y para reunir nuevos conocimientos, fue eregida, en Hüls, una-vivienda experimental sin tomar en consideración el aspecto de la rentabilidad.

El proyecto estaba previsto bajo una idea: gran agilidad, poco peso, corto tiempo de trabajo con montaje seco, buen aislamiento térmico, considerable resistencia a la corrosión e insensibilidad a animales dañinos. Además, debe considerarse la posibilidad de una producción económica en gran escala con variedad de formas y un montaje por obreros poco calificados. En la vivienda experimental los cimientos de hormigón son poco profundos y la estructura es ligera y preparada con perfiles de acero como los usados para la colocación de vidrios. La construcción es arriostrada en su parte superior, empleando en las esquinas pilares de hormigón o de mampostería. Las celosías, el techo y las paredes divisorias son del tipo «sandwich» - elementos de los más diversos modos de construcción-. El tejado es de simple vertiente en construcción ligera con tubos de acero y recublamiento de poliéster. En principio, podemos decir que los dos elementos más importantes entre los productos de materias sintéticas para la construcción son el cloruro de polivinilo (Vestolit) y el poliéster (Vestopal). Más recientemente se ha situado, en primer plano, el polietileno a baja presión (Vestolen A). Además, en un futuro próximo, se abrirán posibilidades de empleo para el polipropileno (Vestolen P). Ya desde hace años están dando buenos resultados el caucho sintético (Litex) y el polímero mixto (Vilit), así como el poliéster, en la técnica de pinturas y en la protección de superficies. Junto con los materiales de construcción tradicionales, los materiales sintéticos se han abierto muchos campos de utilización en la construcción industrial y de viviendas, completados por otros en usos domésticos. Los campos de acción en su aplicación se pueden resumir en seis grupos principales: aislamiento, revestimiento y abastecimiento, pintura, usos domésticos y otros elementos de construcción como chimeneas de humos, bajantes, etc.

En la exposición ordenada sistemáticamente se mostraban con ejemplos prácticos las posibilidades de empleo de las resinas poliéster (Vestopal). Estas materias sintéticas tienen una alta resistencia a la corrosión y son resistentes frente a gran número de agentes químicos. La resina pura se usa en la práctica sólo para trabajos especiales por la gran retracción (del 6 al $8 \%$ en volumen) que tiene lugar durante la polimerización. Añadiendo materiales de carga; tales como fibra de vidrio, haritıa de cuarzo, creta, arena y similares, disminuye la retracción en más de la 
mitad. Desde hace algún tiempo se usa el Vestopal para capas aislantes y protectoras y se obtiene una buena impermeabilización, sobre todo en pozos clarificadores, canales y revestimiento de túneles. Se aplica por procedimiento manual o mecánicamente por inyección. Con los dos procedimientos se preparan capas impermeables y protectoras de buena calidad. En Hüls se usan los dos procedimientos en su aplicación a la construcción. Como muestra la experiencia, en las diversas obras de construcción dentro de la fábrica de Hüls, no se han presentado en las capas impermeables y protectoras síntomas de desgaste después de tres años y medio de exposición. El Vestopal se aplicó, en parte, sobre hormigón viejo ya fraguado, y en parte, sobre hormigón fresco. Puede soportarse hasta cierta humedad en el hormigón sin que la aplicación resulte perturbada.

En Hüls se prepararon una serie de envases de hormigón que recogen líquidos procedentes de la industria química, a todas las concentraciones y a las temperaturas más variadas, recubiertos con una capa impermeable de Vestopal reforzado con fibra de vidrio $\mathrm{y}$, además, con un relleno antiácido. Los resultados han sido excelentes en todos los casos.

A causa de la alta adherencia de las resinas poliéster sobre acero y hormigón, era natural aplicarlas para revestimientos. Ya en el año 1955 se construyó, en Hüls, un puente para paso de tuberías y peatones sobre el canal lateral de Lippe, con una luz de $55,80 \mathrm{~m}$, cuyos elementos de construcción en acero están unidos por medio de un adhesivo. Para asegurar la viabilidad del canal debajo había que emplear, además, tornillos en su parte inferior. Sin embargo, los agujeros donde se introducían los tornillos eran mayores en diámetro que el propio tornillo, de modo que sólo llegaran a soportar carga cuando ceda el adhesivo y los tornillos toquen el borde interno del agujero. Es cierto que, entonces, el puente desarrollaría una flecha muy grande, pero, hasta la fecha, el adhesivo ha mostrado ser completamente suficiente.

La resina de poliéster manifiesta una gran adherencia sobre el hormigón; por eso ya en el 1957 se desarrollaron, en Hüls, vigas huecas, de hormigón (fig. 1), que se construyeron pegando diversos cajones prefabricados, de hormigón, de $2,50 \mathrm{~m}$ de largo, con mortero de poliéster, creando vigas para puentes de 25 a $30 \mathrm{~m}$ de largo, que luego se pretensaban. El mortero ligante se prepara con Vestopal, al cual se añaden materiales de relleno (generalmente, polvo de cuarzo). La gran alcalinidad del hormigón no influye notoriamente. Las superficies del ligante deben estar protegidas de la humedad. Los ligantes desarrollados hasta ahora permiten temperaturas de preparación hasta de $-5^{\circ} \mathrm{C}$.
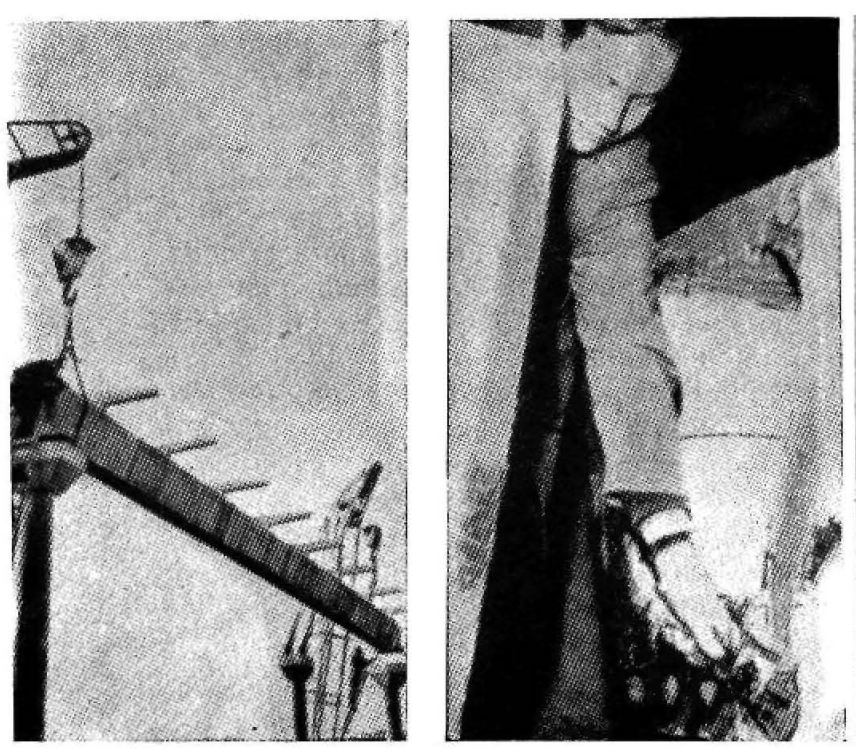

Fig. 1.-Puente-tubo moderno, de hormigón armado, en el terreno de los talleres de la fábrica química de Hüls AG. Los elementos pesados de hor
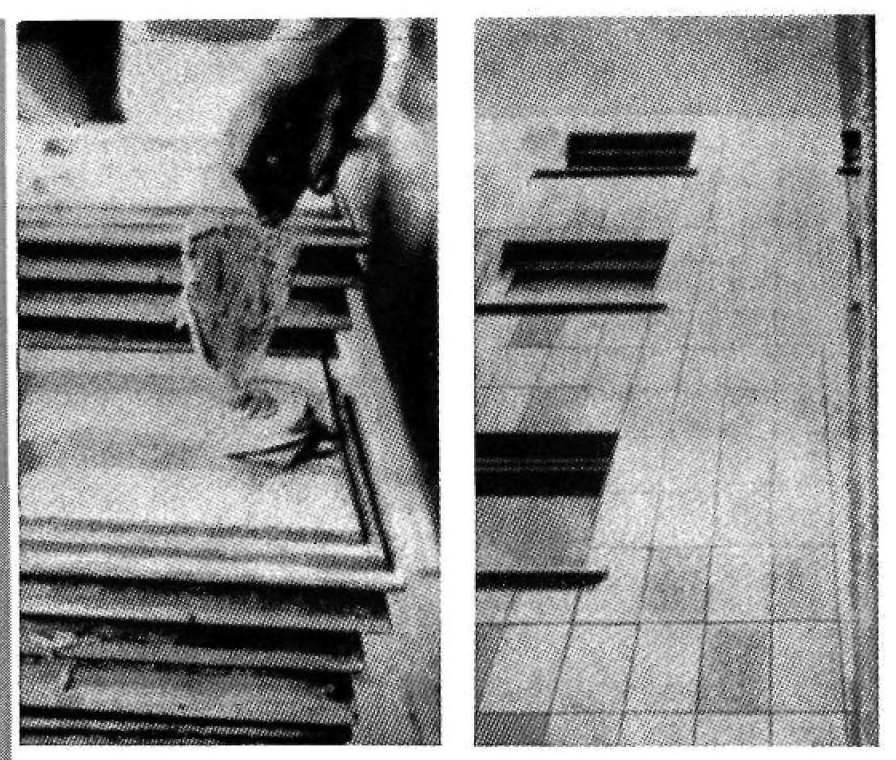

Fig. 2.-Revestimiento moderno de fachada por medio de piedras de hormigón, que fueron pegadas sobre la mampostería con aVestopaln. El pegar se hace en forma de puntos. No se impide la respiración de
las paredes. 
Con ayuda de este mortero de Vestopal fue posible realizar un nuevo revestimiento de fachada. La firma Braas, Frankfurt/Main desarrolló una placa de revestimiento de fachada delgada, lisa y en colores, con hormigón de alta calidad con un resaite en derredor (fig. 2), semejante a una teja flamenca, que impide la entrada del agua de lluvia. Los experimentos de pegar estas placas con ayuda de un mortero de Vestopal, en fachadas, daban buenos resultados, después de haber fracasado otros experimentos de fijación con mortero de cemento. Cada losa se une con la pared sólo por dos sitios, mediante el ligante, con lo cual entre la placa de revestimiento de fachada y la pared del edificio queda una capa de aire. Además, las juntas entre placas quedan sin mortero; de este modo, la pared puede respirar, y los posibles asentamientos del edificio sobre el terreno no dan lugar a la formación de grietas. El poder conglomerante del mortero de Vestopal permite que las placas se puedan fijar sin necesidad de andamio. El conglomerante endurecido tiene una resistencia tal, que es mayor que la de las propias partes conglomeradas $y$, sin embargo, conserva tal elasticidad que cualquier movimiento del edificio no motiva el desconchado de las placas de revestimiento de fechada. Para la prueba definitiva se realizó, en Marl, un experimento, en gran escala, en 24 fachadas de edificios de cuatro pisos. El resultado ha demostrado que las placas de revestimiento de fachadas pueden colocarse correctamente en cualquier punto de la obra y que es posible la realización de los trabajos incluso con mal tiempo. Aún con temperaturas de hasta $-5^{\circ} \mathrm{C}$ y clima seco, los trabajos podían realizarse correctamente.

Como al Vestopal se le añaden materiales de carga de origen de los más variados tamaños de grano, tales como polvo de cuarzo, arenas finas o más gruesas e, incluso, las más variadas clases de gravilla, es posible obtener un revestimiento duro y resistente al desgaste soportando, además, el ataque de casi todos los agentes químicos. Su resistencia a compresión es de más de $1.000 \mathrm{~kg} / \mathrm{cm}^{2}$; la resistencia a la tracción está entre 150 y $200 \mathrm{~kg} / \mathrm{cm}^{2}$ con un módulo de elasticidad relativamente bajo, por lo cual este material se puede emplear especialmente para capas donde el desgaste es enérgico. Es de destacar, sobre todo, que con este material es posible reparar también antiguas o deterioradas pistas de hormigón con garantía de estabilidad. En los terrenos de la fábrica de Hüls se reparó con mortero de Vestopal y harina de cuarzo un viejo hormigón armado, que se estropeó por influencias atmosféricas, desconchado en los bordes o roto en ciertas partes, con las barras de la armadura al aire. Esta masa de mortero impide la entrada de humedad en el hormigón y, con ello, la oxidación de las barras de la armadura. De esta manera se renovó hace cinco años la estructura de hormigón de la fábrica de cloro de Hüls, fuertemente atacada por ácido clorhidrico y vapores de cloro y en parte destruida.

En esta relación de méritos hay que señalar, también, las posibilidades de estos materiales en trabajos de construcción con fines estéticos, sobre todo en la preparación de piedra artificial.

No han faltado tampoco las experiencias para el uso de los materiales sintéticos como elementos de construcción; sin embargo, han fracasado, generalmente, por causa de la termoplasticidad. Con el empleo de armadura de fibra de vidrio se vislumbran nuevas posibilidades. Ejemplos impresionantes de construcciones, en Hüls, con poliéster armado con fibra de vidrio, son las tres chimeneas para aislamiento del ácido. Son tubos de más de $30 \mathrm{~m}$ de altura y, aproximadamente, $1 \mathrm{~m}$ de diámetro y unos 12 a $14 \mathrm{~mm}$ de espesor de pared.

Dentro de la fábrica y en los proyectos de construcción de viviendas llegó a emplearse una lámina creada en colaboración con los productores de plásticos laminados, libre de retracción y aplicable para cubierta del tejado. Después de varios experimentos se trazaron dos caminos:

Uno, la fijación de la lámina contra la masa de betún, por medio de barniz (barniz D-D); y otro, la preparación de una lámina con adición de sustancias polimerizantes. Como en el curso de un año no se observaron señales de retracción, se eubrieron, posteriomente, gran cantidad de nuevas construcciones con estas láminas. Hasta la fecha no se ha observado todavía retracción en ningún caso. Una exposición como la realizada en la fábrica química de Hüls debe tenerse en cuenta en toda la industria de la construcción y fabricación de materiales, porque enseña el desarrollo en la aplicación de materias sintéticas, sus posibilidades $\mathrm{y}$, también, sus limitaciones. 